\title{
Efraín Huerta y José Revueltas: crónica de una amistad literaria (1937-1938)
}

\author{
Antonio Cajero Vázquez \\ El Colegio de San Luis \\ acajerov@hotmail.com
}

\begin{abstract}
RESUMEN: Este artículo intenta, primero, reconstruir la amistad personal e intelectual entre Efraín Huerta y José Revueltas. El pretexto: una carta desconocida de Huerta, injustamente olvidada en la Benson Latin American Collection, de la Universidad de Texas. Luego, se presenta la transcripción de la carta, fechada como el poemario de Carlos Pellicer, Hora de junio, así como una tarjeta donde el remitente explica a su corresponsal por qué no le ha enviado la carta. Ambos testimonios se hallan profusamente anotados con el fin de aclarar las múltiples referencias a personas, lugares, autores, obras y proyectos.
\end{abstract}

Palabras Clave: Efraín Huerta; José Revueltas; cartas; inéditos; amistad.

AвSTRACT: This article attempts, first, to reconstruct the personal and intellectual friendship between Efraín Huerta and Jose Revueltas. The pretext: an unknown letter of Huerta, unjustly forgotten in the Benson Latin American Collection, at The University of Texas. Then, it offers the transcript of the letter, dated as the poems of Carlos Pellicer, Hora de junio and a card where the sender explains why his letter has not sent. Both testimonies are profusely annotated in order to clarify the many references to people, places, authors, works and projects.

KeYwORDs: Efraín Huerta; José Revueltas; correspondance; unpublished texts; friendship.

FECHA DE RECEPCIÓn: 3 de marzo de 2015

FeCha de ACeptación: 23 de noviembre de 2015

$\mathrm{Z}$ n este artículo pretendo rastrear, a partir de varios testimonios desconocidos, el origen de la amistad entre Huerta y Revueltas entre 1937 y 1938. Analizo sucintamente las menciones que se hacen de Huerta en la correspondencia José Revueltas-Olivia Peralta; en los textos donde Huerta alude a Revueltas, ya implícita, ya explícitamente: "Discurso de un joven frente al cielo", "El mundo del quebranto" y "La revolución agredida". Asimismo, en el cuerpo del artículo reproduzco una carta desconocida de Revueltas a Huerta y, debido a su extensión, 
en anexo incluyo la que Huerta escribe a Revueltas mientras éste se halla en Mérida, ruta en que lo habían precedido el mismo Huerta y Octavio Paz.

Aun cuando se ignora la fecha exacta o quién facilitó el acercamiento, resulta verosímil que Huerta y Revueltas se hayan conocido a mediados de 1937. Al respecto, me gustaría expresar la sorpresa de que, hasta donde he leído, nadie haya reparado en la coincidencia de sendos textos escritos por Revueltas y Huerta en fechas próximas. Me refiero al poema "Discurso de un joven frente al cielo", de Revueltas, cuya fecha al pie es "Marzo 31-1937"; aunque en la portada de la plaquette-manuscrito, conservada en el Archivo de Revueltas en la Universidad de Texas, sólo dice "Marzo/1937", el mecanograma que también se conserva en dicho Archivo reza: "Marzo 31 de 1937". La prosa homónima de Huerta se publica el 29 de agosto en El Nacional (2a sec.: 1 y 4). El poema revueltiano presenta claramente tres momentos: 1) la descripción de la noche omnipresente y sus efectos negativos [vv. 1-15], 2) la insurrección contra la apabullante oscuridad [vv. 16-17] y 3) una imperativa solución [vv. 18-24]. Con mayor detalle: primeramente, el sujeto lírico describe el carácter depredador de la noche que "nos está mordiendo [...] hasta sus raíces": dientes, manos, ojos, el cuerpo están amenazados por "la más concreta de las nadas". La noche, en su "espesa cárcel”, tortura al sujeto hasta la angustia. Contra esta hegemonía de la oscuridad, signo de los malos tiempos, el poeta expresa su rebeldía: "No, con todas mis fuerzas, / con todos mis siglos ¡no!” Al final, fortalecido por este gesto de rebelión, expresa un impersonal acto imperativo:

Hay que oír nuestro cuerpo asombroso componiendo paisajes.

Oír la infinita dimensión del poro, y este correr ardiente de la sangre los oídos pegados a las venas. (Revueltas, “Discurso..." [3])

Es evidente una doble gradación; la primera en que la noche invade al sujeto lírico: la noche azota, muerde, desnuda; patea los dientes, hace las manos trémulas, vacía los ojos, degüella el llanto, ahoga el grito; noche que lleva a la nada y sepulta al hombre en un sentimiento de 
angustia que hunde y ensombrece; la segunda, en contrapunto, arranca con una explícita negativa a resignarse a la oscuridad con una fórmula imperativa aligerada por el impersonal "Hay que..."

La historia del texto de Huerta, me parece, encierra un mayor misterio: primero porque se publica casi medio ańo después de la fecha de factura del poema revueltiano (el 29 de agosto de 1937); luego porque obliga a preguntarse a santo de qué los títulos coinciden; finalmente, más preguntas: ¿Huerta y Revueltas fueron testigos de que un joven se rebelaba contra la mordiente noche ante una concurrencia impávida? ¿Huerta dedica su crónica a escoliar el poema de Revueltas? ¿Se pusieron de acuerdo para escribir sobre un mismo tema? ¿Vieron una misma película, leyeron un mismo libro? Cualquiera que haya sido el motivo para que estos espíritus paralelos convergieran, importa destacar el ímpetu de ambas posiciones: en el caso de Revueltas, contra la noche que el día, el alba acaso, puede proscribir. El de Huerta, más político, asume el tono de la arenga explícita desde su foco de irradiación: un "joven revolucionario" que discurre sobre el amor ante el auditorio equivocado. Cito enseguida el fragmento de la prosa huertiana que más dialoga con el poema de Revueltas; también hay un cuerpo que se conmueve, miembro a miembro, con el "discurso frente a las fuerzas celestiales":

Siguió diciendo que "algo se nos ha pegado y empaña la piel y la sonrisa”. Hay quien nos retuerce los dedos hasta las lágrimas; alguien que nos arańa los pulmones; alguien que vuelve espeso el aire hasta que no se oye el grito. Sus palabras volaban, veloces, precisas como una frase de Lenin, y se nos metían por los poros de la epidermis (Huerta, "Discurso...": 1).

Las imágenes entre el poema y la prosa guardan correspondencias innegables: en ambos casos el cuerpo aparece fragmentado por un agente externo; no la noche de Revueltas, sino "algo", "quien", "alguien", se pega en la piel, en la sonrisa; retuerce los dedos, hace llorar, araña los pulmones, oprime el grito. Los temas del discurso del joven camarada se centran en la paz y el amor, sentimientos suplantados por la "soberana estupidez y la venenosa rutina”. Por ello, Huerta considera preciso liberar de esta tiranía, con amores absolutos, totales, amplios, a "la gran masa de jóvenes, víctimas inconscientes de amores incontrolables y desencaminadores" ("Discurso...": 4). Curiosamente, y quizá por ello, Huerta 
disfraza la referencia, estas ideas se basan en una cita de El amor loco, de Breton (1937), ${ }^{1}$ erróneamente atribuida a Paul Éluard. En lugar del impersonal "Hay que...", Huerta emplea, en modo imperativo, la primera persona del plural que domina su texto para exhortar a los jóvenes a reinventar el sentimiento amoroso:

Desarrollemos gestos y actitudes; prefiramos vivir con suma audacia el instante que nos ha tocado, sin temor a asechanzas de los enmarañados mentales, sin miedo a las cuchilladas de los que sólo nacieron para contemplar... y ser contemplados. Nos basta un puñado de gallardía para vibrar libremente y conseguir un triunfo copioso, que sea como un nuevo latido en el clima espiritual de los hombres ("Discurso...": 4; cursivas mías).

Como se observa, Huerta no pierde la oportunidad, por un lado, de atacar a sus contrincantes del momento (¿̨los Contemporáneos, los fascistas, los cedillistas?) y, por otro, de hacer proselitismo a favor de la causa comunista. Así adquiere sentido el tratamiento que confiere al joven rebelde: revolucionario, camarada. A las marañas mentales y el espíritu contemplativo Huerta opone el amor, la audacia, la gallardía, a fin de contribuir con el triunfo universal de la humanidad, seguramente bajo el mando de la URSs.

Allende esta significativa casualidad, lo cierto es que las alusiones a Huerta en la correspondencia publicada de Revueltas inician en mayo de 1938, una semana después de que éste arribara a Mérida, enviado "por la comisión nacional juvenil del comité central del partido, y delegado del cen de las J[uventudes] S[ocialistas] U[nificadas] de M[éxico]" (Revueltas 1987:140). En ésta, Huerta aparece referido como bienhechor en una carta de Revueltas a su Solveig (Olivia Peralta, con quien se había casado en 1937):

¿Leíste ya el artículo de Efraín Huerta (El Nacional, 16 de mayo) sobre El quebranto? Yo lo leí accidentalmente porque aquí no compro $E l$ Nacional. Resulta que los compañeros de Juventudes me presentaban como "escritor", con la consiguiente sorpresa de mi parte, hasta que me

${ }^{1} \mathrm{He}$ aquí las palabras de Breton citadas en el texto huertiano: "Día llegará en que el hombre sabrá reconocerte [amor] como un solo dueño y honrarte hasta en las misteriosas perversiones de que te rodeas" (ápud Huerta, "Discurso...": 1 y 4; cfr. también Breton: 87). 
preguntaron por El quebranto, cosa que me asombró más aún y por la cual pude saber que la primera crítica literaria que sobre mí se ha escrito había aparecido ya. No está mal. Le agradezco mucho a Efraín esa desinteresada atención que tiene para conmigo (144-145). ${ }^{2}$

Esta "primera crítica literaria" que merece la inédita novela de Revueltas, El quebranto, demuestra que, antes de publicar el primer capítulo en Taller, Revueltas hizo todo lo posible por darla a conocer aún en su versión manuscrita. ${ }^{3}$ Asimismo, habría que subrayar la mala suerte de esta novela, porque a pesar de los intentos de publicarla no hay resultados positivos. Así, cada que alude a El quebranto en su correspondencia, Revueltas se resigna a no verla en letra de imprenta, verbigracia el 18 de julio: "Ya no me preocupa si El quebranto se edita o no. Me agradaría que saliera, naturalmente, pero no tiene importancia. Lo que estoy escribiendo me parece mejor, más sólido y profundo, más modesto" (173). En esta cita, de paso, se puede datar la redacción de Los muros de agua que Revueltas habría iniciado en junio durante su periplo yucateco. Este aparente desapego de su primera novela lleva a Revueltas a tomar una decisión radical más de un año después: el 7 de noviembre de 1939, pide a Olivia que busque a Elías Nandino para que, a su vez, retire los originales de El quebranto de la imprenta de Ángel Chápero (cfr. 1987: 183).

En "El mundo del quebranto", Huerta destaca el carácter juvenil de Revueltas, quien "es muchos hombres a la vez y un solo revolucionario"; por esta cualidad, escribe al mismo tiempo versos a su Jenny (igual que el joven Marx) y manifiestos de lucha dirigidos a sus camaradas; el autor de Los hombres del alba aprovecha, asimismo, para revelar el paradero de Revueltas, quien salió comisionado a mediados de mayo de 1938 hacia las "amables tierras de Yucatán, donde es seguro que no se la pasa mal charlando sobre literatura con Ricardo Cortés Tamayo" ("El mun-

${ }^{2}$ En otra carta, el 9 de junio, Revueltas escribe: “Te adjunto el recorte del artículo de Efraín sobre El quebranto. Ya ayer te envié mi artículo del Diario [del Sureste] sobre Bruno Traven" (153).

${ }^{3}$ Antes que Huerta, Silvestre Revueltas había enviado a José sus agudos y rigurosos comentarios sobre El quebranto en una carta del 19 de abril de 1938 (ápud 1987: 326-327); José, también por escrito, aceptará la crítica con cierta resistencia: "Aunque, como ves, te doy la razón en todo, ya no quiero modificar lo escrito. Quizá algún tiempo después escoja el mismo tema para escribir algo más desarrollado y más claro" (135). 
do...": 1). En general, "El mundo del quebranto" deviene un cargado elogio del camarada más que del novelista. Huerta observa cómo la cárcel rompe en dos el destino de cualquier hombre que deja la mitad del mundo tras las rejas. Este mundo del quebranto es un lugar de negación, atiborrado de "pequeñas bestias" ávidas de carne nueva, de nuevos presos a quienes estafar, intimidar, dominar y violentar. El crítico, sin embargo, se niega a detallar el mundo raro y nebuloso construido por Revueltas, sólo comparable con los orfanatorios y los manicomios; recomienda, mejor, que se conozca la obra y a su autor: "Una y otro son la verdad con la pura piel sobre la carne, los huesos y la red arterial" ("El mundo...": 1).

Unas semanas más tarde, el 5 de junio, Revueltas expresa su indignación a Olivia cuando el entonces director del Diario del Sureste (Humberto Lara y Lara) alude a Huerta como "mal poeta, que ha formado sociedad de elogios mutuos con Clemente López Trujillo"; enseguida de esta anécdota, Revueltas vindica a este camarada que se embarca a las primeras de cambio:

Efraín es un buen camarada y se siente comunista. ¡Está muy bien! Le mandé una carta — no te había dicho nada—, llena de pasión, de violencia. Era un llamamiento al trabajo, ya que la revolución pide más actitud constructiva ahora que discursos y actitudes. Contestó, como se debe, en un artículo - me parece que es su primero- sobre la revolución agredida (El Nacional, 2 de junio) donde no desiste de hacer una inútil referencia a mí. Digo inútil porque al leerlo yo entendía de todas maneras — y la cosa no debiera pasar de él y yo solamente- de que se trataba de un acuerdo mutuo, de un deseo mutuo de luchar siempre con nuevas fuerzas. Naturalmente que esto está mejor que las orquídeas, y se lo voy a decir (1987: 150-151).

Impelido por la carta de Revueltas, aún perdida, Huerta denuncia el reciente levantamiento de Saturnino Cedillo, sin nombrarlo siquiera, aunque la asonada le sirve para justificar el título de su artículo, "La revolución agredida". En éste, Huerta invita a sumarse a la revolución cardenista desde todas las trincheras: "aquel que, en los precisos marcos de la Revolución, compone música, escribe manifiestos, hace labor literaria o es un sencillo militante, ya puede estar seguro de haber hecho lo más alto y digno bajo el sol" ("La revolución...": 3). Como se puede notar, hay una sutil alusión a los Revueltas, al músico y al literato; faltó 
Fermín, el pintor. La "inútil referencia” a Revueltas en el artículo de Huerta, considero que ocurre en, al menos, dos pasajes: una alusión implícita: "La Revolución —y aquí deseamos aprovechar las ideas de un camarada lejano — no se alimenta de principios turbios ni canallas"; otra, explícita: "La Revolución Mexicana — citamos a José Revueltas- nos quiere construyéndola, ayudándola en sus problemas'. Ayudar, crear, construir — no olvidaremos nunca su mensaje a la Juventud, señor Presidente- es obligación y tarea nuestra" ("La revolución...": 3 y 5). Como se observa, Huerta no sólo honra al "camarada lejano", en lo individual; en lo colectivo, llama a la solidaridad con el presidente Cárdenas en esos momentos de inestabilidad política.

Curiosamente, aunque en la citada carta a Olivia (del 5 de junio) se propone agradecer la alusión huertiana del 2 de junio en "La revolución agredida", Revueltas ya había enviado su respuesta a Huerta un día antes, como lo demuestra la carta que reproduzco enseguida: ${ }^{4}$

Mérida, Yuc.

Junio 4 de 1938.

Efraín Huerta.

Plaza de Santiago 11.

México, D.F.

Querido Efraín:

He leído tu respuesta en El Nacional del día 2, ${ }^{5}$ ¡muy bien! Está mejor, naturalmente, que las orquídeas y los tranvías de Clemente $^{6}$ (hay que decírselo a él mismo, todos lo consideramos de mucho talento pero es inconcebible perder el tiempo hoy - aunque yo no tengo derecho a hablar, después de que por mi parte lo pierdo tanto-). La referencia a mí en el artículo es completamente

${ }^{4}$ La carta pertenece al archivo de Andrea Huerta. Agradezco a la generosidad de Emiliano Delgadillo, quien me ha dado a conocer este valioso documento que permite reconstruir el periplo de Revueltas en Yucatán y, además, completa parcialmente el rompecabezas de la amistad entre Revueltas y Huerta.

${ }^{5}$ Efraín Huerta. "La revolución agredida". El Nacional, 2 de junio de 1938: 3 y 5.

${ }^{6}$ Se refiere a Clemente López Trujillo, quien fue director del Diario del Sureste, franquicia de El Nacional en Mérida; en esas fechas también se desempeñaba como redactor de El Nacional. 
innecesaria. Tú sabes bien que entre [nosotros] hay ya un lenguaje convenido que no necesita de alusiones objetivas.

Hablando de otras cosas —¿de qué es posible hablar? - te diré... bueno, ¿̨pues qué te diré? Nada, trabajo y estudio. Leí unas maravillosas páginas de Verlaine (me gusta más su prosa que su poesía, quizá sea por los traductores): un estudio sobre Baudelaire y algunas notas de viaje. ${ }^{7}$ Algo deliciosamente escrito, con mucha agilidad, agudeza, y verdadero estilo. Hoy leo, como puede hacerlo cualquier joven soviético, un estupendo libro sobre el Polo Norte: renos y tormentas, y el "Krasin" que tuvo el glorioso honor de salvar a los valientes expedicionarios italianos, ¡qué lecturas más sanas son éstas!

Hice dos artículos para el Diario [del Sureste], que quién sabe si publique su ilustre Director (un personaje ya bastante entrado en años, creo que condiscípulo del viejecito Urbina) enemigo acérrimo de los "modernos", ¡hazme el favor! Quizá lo conozcas: Lara y Lara (parece un toque de corneta) que no se expresa muy bien de ti que digamos. ${ }^{8}$

Uno de estos artículos es sobre Earl Browder y su discurso en la X Convención del Partido Comunista Americano. ${ }^{9}$ Cada vez pienso más en este discurso. No, no puede ser un accidente que el movimiento comunista mundial vuelva los ojos a la tradición de cada pueblo: vuelva los ojos en EE. UU. a Lincoln y Jefferson; en Francia a Robespierre y Marat y toda la inmensa, colosal, cultura francesa; en México (¿en México? Todavía no hemos sabido volver a las tradiciones realmente mexicanas). No fue por acuerdo del 7o Congreso; ha sido una imposición violenta de la vida. Ella se ha levantado por sí misma ante el peligro fachista, es una simple, natural, extraordinaria rebelión de la cultura contra el fachismo: por eso tenemos ahí, en nuestras vidas de hoy, en nuestra sangre, en nuestra actividad, en nuestros discursos, en nuestras palabras dichas o escritas, una voz tremenda, toda una voz de siglos que nos dicta mejor que la circunstancial y objetiva sujeción a una táctica.

${ }^{7}$ Véase más abajo el juicio de Huerta sobre Verlaine y Baudelaire.

${ }^{8}$ También lo hace saber a Olivia el 5 de junio (véase arriba).

${ }^{9}$ El 5 de junio de 1938, Revueltas comenta a Olivia que ha escrito dos artículos para el Diario del Sureste, "uno sobre Bruno Traven y su Puente en la selva, del que ya te había hablado. Salió regularcito. Y otro, que se llama 'H. P. de América', sobre Earl Browder" (1987: 150). 
Ahora quiero que me escribas directamente. No tengo noticias de los muchachos. He querido escribirles pero temo que no lleguen las cartas pues no me han contestado las que les dirigí hace poco. No sé si la Revista ${ }^{10}$ saldrá por fin o quedó en veremos. Qué problemas tienen en Juventudes etc. Si tú puedes decirme algo, te lo agradeceré mucho.

Saludos a todo mundo. A Octavio Paz, a Quintero Álvarez, a $\mathrm{RyR}^{11}$ y palomilla. (Aunque no la conozco sino superficialmente, saludos a Mireya.)

Aux Revoir,

Rev.

El agradecimiento de Revueltas es un pretexto para hablar de la situación en Estados Unidos, donde el Partido Comunista dirigido por Earl Browder toma una vía no prevista en el $7^{\circ}$ Congreso de la Internacional Comunista (agosto de 1935). No obstante que el rumbo tomado por Browder infringe los dictados del Kremlin, Revueltas lo justifica como "una imposición violenta de la vida" ante el inexorable ascenso del fachismo. También es muestra del temperamento y de la heterodoxia de Revueltas, lo que le valió la expulsión del Partido en varias ocasiones. Véase el ímpetu expresado en la defensa de esta interpretación:

[La vida] se ha levantado por sí misma ante el peligro fachista, es una simple, natural, extraordinaria rebelión de la cultura contra el fachismo: por eso tenemos ahí, en nuestras vidas de hoy, en nuestra sangre, en nuestra actividad, en nuestros discursos, en nuestras palabras dichas o escritas, una voz tremenda, toda una voz de siglos que nos dicta mejor que la circunstancial y objetiva sujeción a una táctica.

Como quien dice, Revueltas defiende la solución práctica de las necesidades existenciales cuando la táctica de las ideologías resulte insuficiente. La carta cierra con las quejas naturales de quien vive alejado de los suyos: el reclamo de corresponsales, los saludos de rigor, y la exigen-

${ }^{10}$ Probablemente, Revueltas pregunta a Olivia y a Huerta por una revista que se habría convertido en El Popular, cuya salida a la luz pública fue el 1 de junio de 1938. ¿La revista abortada sería Señales de México, la publicación que Huerta menciona en su carta anexa?

${ }^{11}$ La referencia a estos amigos (Octavio Paz, Alberto Quintero Álvarez y Enrique Ramírez y Ramírez), se reitera en la carta de Huerta que recupero abajo. 
cia de noticias de los frentes político y literario también son constantes en las cartas a su esposa.

Luego, el 9 de junio, Revueltas remite a Olivia los recortes de dos textos significativos en la crónica de esta amistad anunciada, uno de Huerta y otro suyo: "Te adjunto el recorte del artículo de Efraín sobre El quebranto. Ya ayer te envié mi artículo del Diario [del Sureste] sobre Bruno Traven [específicamente sobre Puente en la selva]" (1987: 153). ${ }^{12}$ En otra misiva, fechada en Mérida, "junio 22 de 1938", Revueltas alude a la carta que reproduzco, anotada, en el apéndice: "He recibido carta de Efraín, que dice de mi amistad que le parece encantadora" (160). En el noveno apartado de su carta, Huerta escribe: "Si he de ser sincero, creo que aquí apenas existías, Pájaro, y que fue allá donde te descubriste para mí. Estoy encantado, es decir, que tu amistad es encantadora" (véase abajo). Con ello, la nota y la carta de Huerta pueden datarse entre el 8 de junio en que se publica el artículo sobre Puente en la selva y el 22 de junio en que Revueltas da cuenta de su recepción. Finalmente, el 23 de julio de 1938, éste aludirá a otro testimonio epistolar acaso perdido: "Efraín Huerta me envía una hermosa carta, llena de sinceridad y de poesía. Hace algún tiempo no le envío mis artículos. Harías bien en enseñárselos" (1987: 176). Hasta aquí los registros de Huerta en la correspondencia revueltiana.

Ahora la carta desconocida de Efraín, una prueba reveladora en varios sentidos: porque confirma el fuerte lazo que lo unía a Revueltas; permite establecer fechas de ciertos eventos; muestra la fe de Huerta en el trabajo de su camarada; en fin, arroja datos poco conocidos (y hasta desconocidos) por los propios estudiosos del guanajuatense: verbigracia que Huerta aparece como director de Ahora. El Periódico de la Juventud; que ya tenía preparado Los hombres del alba (con autorretrato y todo); que trabajaba con varios proyectos simultáneamente; que tenía una gran influencia en el círculo de Taller Poético, hecho que no ocultaba en absoluto. La mentada carta está fechada como el poemario de Pellicer, Hora de junio, de 1938. A primera instancia no puede saberse a qué año corresponde; pero los proyectos y los trabajos referidos por Huerta, casi todos, aparecieron publicados en El Nacional en junio de 1938. No se trata de una carta desnuda, sino acompañada por una

${ }^{12}$ El 8 de junio, Revueltas probablemente aludía al artículo sobre Traven: "Te adjunto artículo aparecido hoy en El Diario del Sureste. A ver qué te parece” (152). 
especie de tarjeta donde Huerta explica (y se disculpa de) por qué la carta no ha llegado a las manos de su destinatario, un hasta ahora poco difundido y tierno sobrenombre que Huerta aplica a Revueltas: "Pajarito". Véase el texto completo de la captatio benevolentiae que representa la tarjeta mencionada:

[ca. junio de 1938]

Pajarito: ${ }^{13}$ la "carta" adjunta no te la había mandado por impertinencias del cajero del periódico. A Ricardo [Cortés Tamayo] ${ }^{14}$ le mandé la suya con un esfuerzo que me dejó sin cigarrillos. En serio, la pobreza mía es alarmante. ¡Hombre!, acabo de leer Hombres sin mujer, de Carlos Montenegro. ${ }^{15}$ Aquí está dialogado, novelado, expuesto en toda la crudeza el problema, la denuncia que tú planteas en El quebranto. ${ }^{16}$ Escribiré un artículo, si bien no tan bueno como el tuyo sobre B[runo] Traven ${ }^{17}$ (soy un mentiroso que dice siempre la verdad), ${ }^{18}$ al menos bastante aceptable. Necesito leer los poemas de Carlos Marx a su Jenny —-jenny Lind?-—. ${ }^{19}$ Hum-

${ }^{13}$ Apelativo que Huerta usa para denominar a Revueltas; más abajo, lo sustituye por "Pájaro".

${ }^{14}$ Amigo de Revueltas y Huerta que, desde principios de 1937, estaba adscrito a la Escuela Secundaria Federal para Hijos de Trabajadores, en Mérida. Cortés Tamayo tenía a su cargo la clase de Lengua Nacional; en mayo de 1938, Revueltas se sumaría a este proyecto.

${ }^{15}$ Carlos Montenegro. Hombres sin mujer. México: Masas, 1938.

${ }^{16}$ Huerta había publicado para entonces "El mundo del quebranto". El Nacional, 16 de mayo de 1938: 3. Luego publicó "Hombres sin mujer". El Nacional, 25 de junio de 1938: 3 .

${ }^{17}$ Huerta se refiere al artículo de José Revueltas sobre Puente en la selva, en Diario del Sureste, Mérida, 8 de junio de 1938.

${ }^{18}$ La expresión entre paréntesis coincide con una máxima de Jean Cocteau, "Je suis un mensonge qui dit toujours la vérité", incluida en Journal D'un Inconnu, cuya primera edición es de 1953 (agradezco el dato a la generosidad de David Huerta).

${ }^{19}$ Alude a la esposa de Carlos Marx: Johanna Bertha Julie Jenny von Westphalen (1814-1881). Jenny Lind (1820-1887) fue una cantante de ópera sueca que Revueltas conoció por medio de un poema de Gorostiza, como lo expresa a Olivia, su "Jenny Lind": "No creerás seguramente que te digo Jenny Lind por las mismas razones que Amiel tenía para poner motes a la persona amada. No. Lo hago porque me parece algo extraordinariamente juvenil. Jenny Lind es un personaje de un precioso poema de Gorostiza o Salvador Novo, no recuerdo. Más tarde podré decirte con igual jovialidad el dulce, apasionado y sońador nombre de 'mi adorada Lady Jane" (1987: 109). Gorostiza homenajea a la prima donna en "Acuario" (1925: 39-40). Como se observa al final de esta última cita, Revueltas alude a El amante de Lady Chatterley, de Lawrence, 
berto Ávalos ${ }^{20}$ lee a Descartes; [José] Mancisidor se idiotiza más; y yo, Yo soy un pulso herido, etc. ${ }^{21}$

Huerta nunca escribe gratuitamente: en esta tarjeta explica el retraso en el envío de su carta, y se las arregla para recomendar a Revueltas la lectura de Hombres sin mujer, del cubano Carlos Montenegro, ya que desarrolla un asunto semejante al de El quebranto. Le anuncia, de la misma forma, que dedicará una reseńa a la novela de Montenegro y le comenta la urgencia que tiene de leer los poemas de Marx a Jenny Lind (personajes ya citados en su comentario sobre El quebranto tres semanas antes). Al final de la tarjeta, Huerta informa a su corresponsal sobre dos de sus colegas que había olvidado mencionar en la carta de "Hora de Junio": Humberto Ávalos y José Mancisidor, de los cuales éste sale peor parado.

La carta fechada o titulada "Hora de Junio", se halla escrita en papel membretado de Ahora. El Periódico de la Juventud: director, Efraín Huerta; jefe de redacción, Cinosura Constantino; secretario de redacción, Humberto Ávalos; director gráfico, Luis Arenal; administración, Olivia Peralta (sí: la primera esposa de Revueltas); por último, jefe del departamento de publicidad, Raúl Rivas Cid. Según reza el membrete, las oficinas del periódico estaban en Luis González Obregón, núm. 23. Otra tarea para la crítica huertiana: localizar esta publicación y recuperar los pormenores en torno de ella.

Por medio de la extensa carta dividida en diez secciones, Huerta apabulla a Revueltas con sus proyectos: "Rehabilitación de las palomas", con citas de García Lorca y Gerardo Diego, no sólo reivindica palomas, sino seres humanos marginados como los negros del Harlem y otros más. "Rosario y sus cantores" se halla dedicado a una antología sobre los

a cuyo personaje femenino remite Huerta en "Lady Jane y la poesía", artículo donde elogia superlativamente Raiz del hombre, de Octavio Paz.

${ }^{20}$ Amigo de Huerta que aparece como jefe de redacción de Ahora. El Periódico de la Juventud. También colaboró en El Popular. Por cierto, en el mismo suplemento de Crítica y Orientación Popular en que Huerta publica "Declaración de odio" aparece "Palabra final” de Ávalos (cfr. Delgadillo 2014: 235).

${ }^{21}$ Versos de Federico García Lorca, "Poema doble del Lago Edem”, perteneciente a Poeta en Nueva York: "Quiero llorar porque me da la gana / como lloran los nińos del último banco, / porque yo no soy un hombre, ni un poeta, ni una hoja, / pero sí un pulso herido que sonda las cosas del otro lado" (76). Revueltas también reproduce el último verso en una carta del 22 de abril de 1938, a Silvestre Revueltas (cfr. 1987: 135). 
cantores de Rosario de la Peńa, desde el suicidio de Manuel Acuña hasta principios del siglo xx. "Arturo Serrano Plaja", publicado en dos partes, donde Huerta muestra el desarrollo del poeta español entre Sombra indecisa, de 1933, y Destierro infinito, de 1936. Respecto de Los hombres del alba, cabe señalar que no sólo se encuentra reescribiéndolo, sino que tenía un plan completo sobre el libro, pues ya incluía el autorretrato que acompañará la editio princeps del poemario, como se aprecia en un atinado desdoblamiento: "un retrato mío que hizo el adolescente del imperfecto pincel".

Según se anuncia en el primer número de Taller Poético, en diciembre de 1938, Los hombres del alba sería publicado en las Ediciones del Taller Poético, como Linea del alba; sin embargo, con el advenimiento de Taller, el plan se modifica (aunque tampoco se concreta), como se desprende de una nota de Solana:

Taller publicará un libro de poesías de Efraín Huerta, Los hombres del alba, que reúne su producción de los últimos años. Otro tanto podemos decir de Alberto Quintero Álvarez, que ya tiene listo el original del libro Dos años en una misma ciudad. José Revueltas, por su parte, publicará una novela, El quebranto, de la que nuestros lectores conocen el primer capítulo, publicado en el número dos de esta revista ("Tarjetas": 57).

Ninguno de los tres libros anunciados se publica con el sello de Taller: es más, de Dos años en una misma ciudad se conoce sólo el título (también anunciado en el primer Taller Poético); después de perder los originales corregidos de El quebranto, Revueltas no verá publicado siquiera el borrador que conservó Olivia Peralta.

Acaso por solicitud de Revueltas, Huerta hace gestiones para publicar El quebranto; sin embargo, no logra convencer a los editores o a sus amigos, unos y otros abarcables en el apóstrofe de su misiva: "Los 'canallas' no quieren publicar El quebranto. Y claro, he protestado. Intentan, a esto no me opongo totalmente, lanzarlo en unos cuadernos que amamantará no sé si Xavier Icaza o la del Mar”. Revueltas, por su parte, también se esmeró por publicar El quebranto, si bien con magros resultados, por lo que asume una suerte de resignación cada que menciona dicha novela en su correspondencia, como en la carta a Olivia del 18 de julio de 1938: "Ya no me preocupa si El quebranto se edita o no. Me agradaría que saliera, naturalmente, pero no tiene importancia. Lo que estoy escri- 
biendo me parece mejor, más sólido y profundo, más modesto" (1987: 173). En diciembre de 1939, ocurrirá un incidente lamentable durante su estancia en Guadalajara después de un conflicto con la Comisión Nacional Juvenil, del Partido Comunista: ${ }^{22}$ en el tren, le roban su maleta con los originales de El quebranto corregido. Así lo registra en su correspondencia: "Pierdo totalmente El quebranto (lo cual ni me apena ni me regocija)" (189). El 18 de diciembre, no obstante, se hará más patente la pérdida en un sueño: "Soñé que había recuperado El quebranto. ¿Qué sueño absurdo e idiota! Es una prueba de que subconscientemente he de estarlo lamentando. ¡Abajo el pasado, todo el pasado, el bueno y el malo! ¡Sólo el futuro tiene realidad y auténtica presencia!” (194).

Aparecen nombrados, también en esta carta, todos los amigos (y enemigos) comunes, unos en la península y otros en la capital: Octavio Paz, Elena Garro, Alberto Quintero Álvarez, Ricardo Cortés Tamayo, Humberto Ávalos, José Mancisidor, Enrique Ramírez y Ramírez, César Ortiz, Román Irigoyen, Humberto Lara y Lara, Aurora Díaz y Silvestre Revueltas; las simpatías y diferencias estéticas: García Lorca, Pellicer, Montenegro, Serrano Plaja, Traven, Marx, Zola, Verlaine, Baudelaire, entre otros.

Aun cuando Huerta dedicará otros textos a Revueltas, como la reseńa sobre El luto humano en las páginas de La Voz de México, me parece que la carta de "Hora de Junio", de 1938, representa un testimonio de los fuertes lazos que ambos corresponsales establecieron: una amistad que, como se observa en las fotografías en que Huerta y Revueltas se echan un palomazo en casa de Neruda hacia principios de 1943, los pone en sintonía más allá de las cuestiones ideológicas, de la camaradería partidista: en el plano vital e íntimo. Por supuesto, habría que considerar que documentos como los recuperados en este artículo no sólo llenan huecos informativos, sino que crean, paradójicamente, nuevas interrogantes: ¿qué fue de Señales de México y de Ahora? ¿Dónde está la carta que motiva las menciones de Revueltas en "La revolución agredida”? ¿Quiénes son Román Irigoyen y Aurora Díaz? ¿Qué versión de El quebranto leyó Huerta? Ahí dejo unas cuantas dudas generadas por los hallazgos. Por último, véase la carta de Huerta, íntegra.

\footnotetext{
${ }^{22}$ Revueltas viaja a Guadalajara porque los camaradas de esa ciudad lo acusaron de "haber estado borracho en esta ciudad" en una visita previa. Ante esta acusación y para no enfrentar el citatorio de la Comisión de Disciplina, decide mudarse a Guadalajara para "demostrar a los camaradas de Jalisco que yo soy persona que puede prestigiar al partido” (1987: 188).
} 


\section{Anexo}

Hora de Junio ${ }^{23}$

1

Rev: preparo "Rehabilitación de las palomas", con alusiones de Federico, Pellicer y otros ilustres poetas; ${ }^{24}$ "Rosario y sus cantores", a propósito de un bello libro antológico que me prestó Miréio, o Mireya, o Mireilla, como gustes; ${ }^{25}$ "Arturo Serrano Plaja" ${ }^{26}$ con estudios más o menos bien documentados. Además: corrijo Los hombres del alba. ¡Si vieras los dibujos y el retrato mío que hizo el adolescente del imperfecto pincel! Pero no creo sacar pronto mi libro. ${ }^{27}$

${ }^{23}$ Alusión al poemario de Carlos Pellicer. Hora de junio. México: Hipocampo, 1937. Véanse, como muestra de la admiración de Huerta por Pellicer: "Tres libros de poesía”, donde Huerta declara que Hora de junio es "ya el hit poético del año"; además, considera a Pellicer "maestro de la joven poesía mexicana" (3); en "Verdadero junio", el crítico expresa, entre otros juicios, lo siguiente: "En una hora de junio, alarmando a los estériles y abstencionistas, y como entre voces de ansia satisfecha y prestigio merecido, ha vuelto Carlos Pellicer con nosotros [...] Carlos Pellicer es un ejemplo de auténtico poeta. Es un creador. Es un vigoroso artista lleno de vitalidad [...] Hora de junio es un libro destinado a servir de eje primordial en la maquinaria poética mexicana de muchísimos años" (2). Finalmente, para la encuesta de El Mejor Poeta de México promovida por El Nacional, Huerta expresa su voto por Carlos Pellicer, porque "no pertenece a un pasado cercano como el autor de Los senderos ocultos [Enrique González Martínez], ni comienza a madurar como Octavio [Paz], ni mucho menos es un principiante prometedor como Ramón Gálvez. Pellicer es un señor poeta de tremenda autenticidad, con arraigo en América que difícilmente será superado. Los orígenes universales de su poesía y el gran corazón desangrado en cada uno de sus poemas, le hacen primerísimo poeta de México" ("Voto por Carlos Pellicer": 3).

${ }^{24}$ Publicado en El Nacional, 18 de junio de 1938: 3. Efectivamente, García Lorca y su poesía sirven de eje al artículo de Huerta.

${ }^{25}$ El artículo apareció en El Nacional, 18 de julio de 1938: 3. Huerta juega con el nombre de Mireya Bravo Munguía, su primera esposa. También la denominaba en su epistolario "Andrea de Plata", "Mireyín", "Sirena de Plata", "Duquesita de Plata", "Piernas de Diamante".

${ }^{26}$ Huerta publica un artículo en dos partes: "Arturo Serrano Plaja I". El Nacional, 12 de junio de 1938: 3; "Arturo Serrano Plaja II". El Nacional, 13 de junio de 1938: 3 y 5 .

${ }^{27}$ Efectivamente, el libro no sale pronto, sino hasta 1944. 
2

Señales de México saldrá, a pesar del DAPP. ${ }^{28}$ Es horrible, me encoleriza que se publiquen idioteces a cada rato con dinero del gobierno y un imbécil se oponga — jah, no hay partida en el presupuesto! - a que mensualmente se nos ayude con 200 pesos. No he ocultado frente a $\mathrm{O}$ [ctavio] P[az], A[lberto] Q[uintero] Á[lvarez ${ }^{29}$ y [Enrique] R[amírez] y R[amírez $]^{30}$ mi descontento. Porque será lo de siempre: ver al subsecretario, al oficial mayor, a este diputado, al senador fulano, a ver cuánto pueden o quieren dar cada mes... ¡ Es hacer un Taller Poético! ${ }^{31}$ pobre, humillado, casi vendido.

Mondragón ${ }^{32}$ está escribiéndote, me dijo, una carta en el idioma de nuestro amadísimo Romain Rolland; R[amírez] y R[amírez], elusivo como el Pimpinela Escarlata ${ }^{33}$ — iqué gran película Pedro el Grande; jamás olvidaré los gestos tiernos, tan de eterna alma rusa, del mujik Fedka!Paz, disperso, entregando energías en sitios donde no debiera ni siquiera pararse (vive con Helena ${ }^{34}$ en una casa que renta 75 al mes...); César

${ }^{28}$ Ignoro qué proyecto era Señales de México. En diciembre de 1938, durante el auge del gobierno cardenista, se creó el Departamento Autónomo de Publicidad y Propaganda (DAPP), derivado de la Dirección de Publicidad y Propaganda, que dependía de Gobernación desde su creación en agosto del mismo año.

${ }^{29}$ Poeta y crítico que, junto con Rafael Vega Albela, marca trágicamente a la generación de Taller: nace en 1914 y muere en 1944.

${ }^{30}$ Amigo entrañable de Revueltas, con quien compartía la dirigencia de las Jsum cuando aquél fue expulsado en 1937 y colaborador asiduo de El Popular. Revueltas le dedica "Las evocaciones requeridas", en 1962, en los términos siguientes: "Dedico estas Evocaciones a Enrique Ramírez y Ramírez, amigo entrańable; en materia de nuestra vida política, largamente unidos unas veces, y otras, severamente separados. Nuestra amistad parecería representar la síntesis en que se expresa la dialéctica del corazón humano" (1987: 317).

${ }^{31}$ Publicación dirigida por Rafael Solana entre mayo de 1936 y junio de 1938; alcanzó cuatro números.

${ }^{32}$ Acaso se trate de Luis Mondragón, aludido por Revueltas en una carta del 22 de junio de 1938, a Olivia: "también he recibido carta de los bandoleros del Chamaco y Ramírez, y del tierno [Luis] Mondragón. Saludos a todos” (1987: 160).

${ }^{33}$ Quizás Huerta se refiera al personaje de la baronesa Emma Orczy de Orcz. The Scarlet Pimpernel. Londres: 1905.

${ }^{34}$ Elena Garro, primera esposa de Paz, en cuya relación Efraín Huerta habría fungido de celestina a mediados de 1937. 
[Ortiz], ${ }^{35}$ infantil, movedizo, sacándose punta. El resto, ignoro si existe. Los entreveo en "Le chien andalou", en "Minnie la cándida", ${ }^{36}$ en J. S. U. M. ${ }^{37} \mathrm{y}$, a veces, creo ver un rostro conocido en el patio de leyes, pero no. Luego me entero que Ambrosio, nuestro chamaco de oro, anda por las redes ferrocarrileras, lanzando nutridos discursos que la diabólica Elvira Vargas se encarga de glosar en fáciles gacetillas del Diario al Servicio de la Colectividad.

4

Los "canallas" 38 no quieren publicar El quebranto. Y claro, he protestado. Intentan, a esto no me opongo totalmente, lanzarla en unos cuadernos que amamantará no sé si Xavier Icaza ${ }^{39}$ o la del Mar. ${ }^{40}$

${ }^{35}$ Colaborador de El Popular, conocido como el Chamaco y cuya amistad compartían Huerta y Revueltas. En el número de aniversario del periódico en 1943, se dice de él: "Su admirable dinamismo lo coloca en la primera fila del periodismo nacional. En nuestra colección hay huellas, magníficas muestras, de su capacidad profesional y de su agilidad para captar el ángulo justo de los problemas y de las cosas. Ahí están recientemente sus crónicas del viaje que hizo a los Estados Unidos, invitado por el Gobierno de Washington. Pocos como él habrán comprendido y relatado el esfuerzo formidable del país vecino en la guerra presente. En lo local, sería injusto no hacer mención de su campaña sobre la carestía de la vida, que sin duda es uno de los más poderosos estimulantes que el Gobierno ha tenido para la puesta en práctica de sus medidas recientes" (“César Ortiz”: 1).

${ }^{36}$ Desconozco si son nombres o sobrenombres de cafés; en todo caso, el primero adopta el título de la película de Buñuel (1929) y, el segundo, el de una obra de Massimo Bontempelli (1927), traducida al español y dirigida por Xavier Villaurrutia a mediados de los años treinta.

${ }^{37}$ Juventudes Socialistas Unificadas de México (JSUM), organización que habría nacido hacia mediados de 1935 por iniciativa de Lázaro Cárdenas, luego reformulada, conforme a los acuerdos de la VII Internacional, a finales de 1936 y principios de 1937. Con el pretexto de su "afición a la bebida", Revueltas habría sido turnado a la Comisión de Disciplina de las Jsum y, luego, expulsado de la dirigencia en septiembre de 1937 (cfr. 1987: 128-133).

${ }^{38} \mathrm{El}$ adjetivo bien podría aplicarse a los dirigentes del DAPP, pero también a Paz, Quintero Álvarez, Solana y Ramírez y Ramírez, a quienes Huerta menciona líneas arriba. Lo cierto es que, aun cuando se anuncia en Taller la inminente publicación de El quebranto, junto con otras obras de otros colegas de generación, no será publicado sino un capítulo de la versión corregida por José Revueltas (1939: 15-26) y, póstumamente, la primera versión manuscrita (1983: 33-65).

${ }^{39}$ Xavier Icaza (1892-1969), aunque de manera lateral, formó parte del Ateneo de la Juventud; su obra más conocida es Panchito Chapopote. Retablo tropical o relación de un extraordinario sucedido de la heroica Veracruz (1928).

${ }^{40}$ María del Mar (Ángela Laura Moll Madariaga) nació en la ciudad de México en 1897; autora de El alma desnuda (1925), La corola invertida (1930), Luna en zo- 
"Los chinos ven la hora en los ojos de los gatos". ${ }^{41}$

Baudelaire.

6

Tienes razón. Si no leemos al Pauvre Lelian ${ }^{42}$ en francés, siempre nos chocarán las traducciones de Farrère o Bacarisse. ${ }^{43}$ Muy buena la prosa de Verlaine, pero nada junto a la poesía de Las flores del mal. Entiendo que Ricardo [Cortés Tamayo] te prestó los Poemas en prosa. ${ }^{44} \mathrm{La}$ frase del casillero 5, ¿no te parece una greguería de Ramón ${ }^{45}$ El xix francés es denso. He leído La ralea de Zolá, y, caray, ya no me gusta. Deberías leer, si no lo has hecho, La educación sentimental, de Flaubert. A [Rafael] Solana y a mí nos gusta.

He dado a Mancisidor mi poema "Declaración de amor", 46 a la ciudad nuestra. Me gusta algo, más, desde luego, que la de Odio, en la que fui

zobra (1934), En ti, sólo distante (1937), Cántico del amor que perdura y Tres cartas a Hans Castorp (1939), Sombra de flor en el agua (1943), Luz en la muerte (1945), Canto panorámico de la Revolución (1952), Perfiles de gloria y Horizonte de sueños (1957), Vida de mi muerte (1960), Atmósfera sellada (1961) y Tu rostro derramado (1974). Por ese tiempo, Huerta se halla cerca de sus posibles mecenas a quienes menciona de pasada en "El año poético": "Están, poco después, a una altura aceptable y digna, un libro de María del Mar, En ti solo distante [México: Fábula, 1937], y Marea encendida [México: Letras de México, 1937] de Xavier Icaza, volumen con más pretensiones que poesía” (162).

41 "Les Chinois voient l'heure dans l'œil des chats": línea con que inicia "L’Horloge", de Baudelaire (303).

${ }^{42}$ Anagrama de Paul Verlaine; uno de los seis poetas estudiados por éste en Poétes Maudits (1880).

${ }^{43}$ Por ejemplo, Bacarisse traduce de Paul Verlaine. Antaño y ayer. Poemas. Madrid: Mundo Latino, [1924].

${ }^{44}$ Huerta muestra mayor deferencia por El spleen de París, Las flores del mal y Pequeños poemas en prosa, de Baudelaire, que por la poesía y la prosa de Verlaine. Esta influencia aún descuidada, me parece, resulta definitiva en la poesía primera de Huerta.

${ }^{45}$ Ramón Gómez de la Serna, famoso por haber inaugurado el género de las greguerías con el libro homónimo (1917).

${ }^{46}$ Esta "Declaración de amor" aparece, efectivamente, en la revista dirigida por José Mancisidor: Ruta. 15 de julio de 1938, 2: 23-26. 
muy ingrato. ${ }^{47}$ Tú sabes que declarar mi Amor a todo — soy un amante impenitente-, al mundo, a las mujeres, a los hombres, es un delirio del cual no puedo prescindir. Delirar en torno a la mujer que amo y que me pertenece, al fin, después de cinco años de andar maldito —otra vez el pobre Lelian-, es ya como un sistema sin el que la vida no sería casi posible.

¿Qué estoy diciendo?

Efusivos saludos a Román Irigoyen. Que me escriba algo. Sacude, plea$s e$, el árbol genealógico de ese espermatozoide frustrado que dice llamarse Aurora Díaz; y no hagas caso del cretino gato Lara: ${ }^{48}$ es un pobre politiquillo corroído por la envidia.

A Ricardo [Cortés Tamayo], que me disculpe como pueda. Que ya le escribo unas cosas importantes.

9

Si he de ser sincero, creo que aquí apenas existías, Pájaro, y que fue allá donde te descubriste para mí. ${ }^{49}$ Estoy encantado, es decir, que tu amistad es encantadora.

Saludé a Silvestre [Revueltas] en el Café París. Te saluda. $\mathrm{Y}-\mathrm{M}$ - un abrazo lento, largo de Efraín Huerta

${ }^{47}$ Efraín Huerta, "Declaración de odio". Crítica y Orientación Popular (cfr. Delgadillo: 235). Este poema también fue reproducido en el Suplemento Dominical de El Popular, 5 de octubre de 1941: 3 .

${ }^{48}$ Probablemente se refiera a Humberto Lara y Lara, director del Diario del Sureste, que había hablado mal de Huerta ante Revueltas a principios de junio de 1938. El 12 de este mismo mes, Revueltas lo menciona de pasada: "Llegó de pronto Lara y Lara, director del Diario, y me saludó muy atentamente, sentándose a nuestra mesa: '¿Vi su artículo [sobre Puente en la selva]? ¡Muy bonito, muy bonito!” (1987: 155).

49 “allă": en Mérida, donde Revueltas se encuentra comisionado. 


\section{BiBLIOHEMEROGRAFÍA}

Anónimo. "César Ortiz". El Popular. 3a sec., 1 de junio de 1943: 1.

Baudelaire, Charles. Euvres Complètes. Paris: Gallimard, 1948.

Breton, André. El amor loco. Trad. y pról. Juan Malpartida. 2a ed. Madrid: Alianza, 2008.

Delgadillo, Emiliano. La fragua de Los hombres del alba de Efraín Huerta: 1935-1944. Tesis de Licenciatura. México: Universidad Nacional Autónoma de México, 2014.

García Lorca, Federico. Poeta en Nueva York. Barcelona: Lumen, 1997.

Gorostiza, José. Canciones para cantar en las barcas. México: Cvltvra, 1925.

Huerta, Efraín. "Discurso de un joven frente al cielo". El Nacional, 29 de agosto de $1937,2^{\text {a }}$ sec.: 1 y 4 .

Huerta, Efraín. "Hora de Junio". Junio de 1938. 5 ff. Archivo José Revueltas, Benson Latin American Collection, University of Texas at Austin.

Huerta, Efraín. “[Tarjeta]”. Junio de 1938. 1 f. Archivo José Revueltas, Benson Latin American Collection, University of Texas at Austin.

Huerta, Efraín. "Arturo Serrano Plaja I". El Nacional, 12 de junio de 1938: 3.

Huerta, Efraín. "Arturo Serrano Plaja II". El Nacional, 13 de junio de 1938: 3 y 5 .

Huerta, Efraín. “Declaración de amor”. Ruta. 2 (1938): 23-26.

Huerta, Efraín. "Declaración de odio". Suplemento Dominical de El Popular, 5 de octubre de 1941: 3.

Huerta, Efraín. "El año poético". El Nacional, Suplemento Cultural, 17 de enero de 1938. En Efraín Huerta. Aurora roja. Ed. Guillermo Sheridan. México: Pecata Minuta, 2006: 161-163.

Huerta, Efraín. "El mundo del quebranto". El Nacional, 16 de mayo de 1938: 3.

Huerta, Efraín. "El triunfo legítimo de José Revueltas". La Voz de México, 24 de enero de 1943: s/p.

Huerta, Efraín. "Hombres sin mujer". El Nacional, 25 de junio de 1938: 3.

Huerta, Efraín. "La revolución agredida”. El Nacional, 2 de junio de 1938: 3-4.

Huerta, Efraín. "Lady Jane y la poesía”. El Nacional. 2a sec., 16 de mayo de 1938: 1.

Huerta, Efraín. "Rehabilitación de las palomas". El Nacional, 18 de junio de 1938: 3.

Huerta, Efraín. “Tres libros de poesía”. El Nacional, 1 de julio de 1937: 3.

Huerta, Efraín. "Verdadero junio". Suplementos de El Nacional, 2a ép. Núm. 337, 17 de octubre de 1937: 2. 
Huerta, Efraín. "Voto por Carlos Pellicer". El Nacional, 1 de agosto de 1937: 3 .

Montenegro, Carlos. Hombres sin mujer, México: Masas, 1938.

Pellicer, Carlos. Hora de junio. México: Hipocampo, 1937.

Revueltas, José. "Discurso de un joven frente al cielo". 3 ff. Ms. Archivo José Revueltas, Benson Latin American Collection, University of Texas at Austin. También: José Revueltas. El propósito ciego. Ed. José Manuel Mateo. México: Aldvs-Obranegra, 2001: 23-24.

Revueltas, José. “El quebranto”. Taller, 2 (1939): 15-26.

Revueltas, José. Las cenizas. 2a ed. México: Era, 1983.

Revueltas, José. Las evocaciones requeridas. T. 1. México: Era, 1987.

[Solana, Rafael]. "Tarjetas". Taller, 4 (1939): 57. 